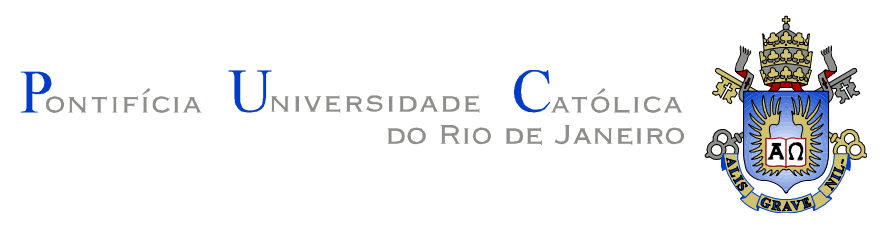

Leonardo Maia Bastos Machado

A formação do conceito de Imagem do pensamento na filosofia de Gilles Deleuze

\author{
Tese de Doutorado
}

Tese apresentada ao Programa de Pós Graduação em Filosofia do Departamento de Filosofia da PUC-Rio como parte dos requsítos parciais para obtenção do título de Doutor em Filosofia.

Orientador: Paulo Cesar Duque Estrada

Rio de Janeiro

Abril de 2009 


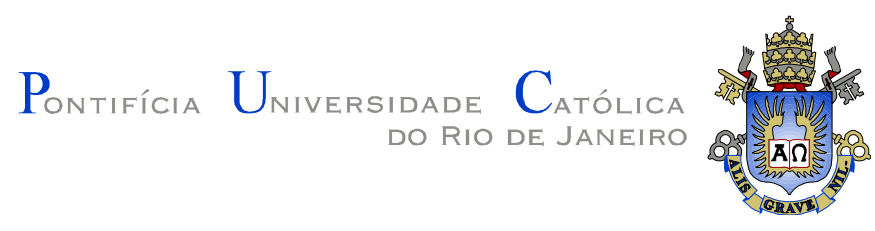

\title{
Leonardo Maia Bastos Machado
}

\section{A formação do conceito de imagem do pensamento na filosofia de Gilles Deleuze}

Tese apresentada como requisito parcial para obtenção do grau de Doutor pelo Programa de Pós -Graduação em Filosofia do Departamento de Filosofia do Centro de Teologia e Ciências Humanas da PUC-Rio. Aprovada pela Comissão Examinadora abaixo-assinada.

\author{
Prof. Paulo Cesar Duque Estrada \\ Orientador \\ Departamento de Filosofia - PUC-Rio \\ Profa. Deborah Danowski \\ Departamento de Filosofia - PUC-Rio \\ Prof. Mario Bruno \\ UFF
}

Prof. Elton Luiz Leite de Souza

UCAM

Prof. Norman Roland Madarasz

UGF

Prof. Paulo Fernando Carneiro de Andrade

Coordenador Setorial do Centro de Teologia

E Ciências Humanas - PUC-Rio

Rio de Janeiro, abril de 2009 
Todos os direitos reservados. É proibida a reprodução total ou parcial do trabalho sem a autorização do autor, do orientador e da universidade.

\section{Leonardo Maia Bastos Machado}

Tem graduação e mestrado em Filosofia. Desde 1999, é professor de Filosofia da Universidade Estadual do Sudoeste da Bahia (UESB). É Editor responsável do APRENDER - Caderno de Filosofia e Psicologia da Educação. Atualmente suas linhas de pesquisa concentram-se em Filosofia francesa moderna e contemporânea e Filosofia da Educação.

Ficha Catalográfica

Machado, Leonardo Maia Bastos

A formação do conceito de imagem do pensamento na filosofia de Gilles Deleuze / Leonardo Maia Bastos Machado ; orientador: Paulo Cesar Duque Estrada. - 2009.

$304 \mathrm{f.} ; 30 \mathrm{~cm}$

Tese (Doutorado em Filosofia)-Pontifícia Universidade Católica do Rio de Janeiro, Rio de Janeiro, 2009.

Inclui bibliografia

1. Filosofia - Teses. 2. Imagem do pensamento. 3. Filosofia da diferença. 4. Filosofia transcendental. 5. Filosofia crítica. I. Duque-Estrada, Paulo Cesar. II. Pontifícia Universidade Católica do Rio de Janeiro. Departamento de Filosofia. III. Título.

CDD: 100 


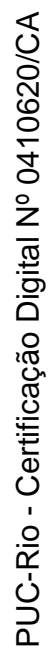

Ao meu filho, Pedro

A minha avó, Francisca 


\section{Agradecimentos}

A rigor, eu deveria me limitar, numa descrição mais verdadeira do processo de "endividamento" ligado a uma tese, a dizer:

A muitas, muitas pessoas... (com reticências, porque a ajuda de muitas foi talvez involuntária, e a de outras, para mim, talvez inconsciente).

Mas, numa lista apenas aproximada, gostaria de fazer algumas menções especiais.

Em primeiro lugar, à Universidade Estadual do Sudoeste da Bahia, pela licença concedida, e pela bolsa de estudos.

Agradeço também, profundamente, ao meu orientador que, sem ser um leitor habitual de Deleuze, abraçou este trabalho. De lá para cá, minha admiração e gratidão para com ele só aumentaram. Em resumo, eu diria que o Paulo Cesar é Ímpar, porque sempre um grande par.

Ao Programa de Pós-Graduação em Filosofia da PUC-Rio, aos seus professores e funcionários pela gentil acolhida, e pela oportunidade de desenvolver um trabalho acadêmico com as condições de excelência desta Universidade.

Agradeço, ainda, em memória, a François Zourabichvili que, numa conversa aqui no Rio em 2004, ponderou-me que a opção pelo estudo da ontologia deleuziana talvez não fosse a melhor orientação para uma pesquisa em Deleuze. Isso me fez errar talvez mais do que devia, protelando a escrita da tese, mas apresentou-me um tema a meu ver mais rigoroso para a leitura de Deleuze, qual seja, o do transcendental como verdadeiro problema deleuziano no pensamento.

Agradeço ainda aos membros da minha banca de qualificação, Professores Elton Luiz e Ovídio Abreu, por suas sugestões e contribuições.

À Zamara, pelos textos, conselhos, e "força".

À Rachel Sapunaru, pelos constantes apoios em matérias puquianas.

Agradeço também à Meire, pelo apoio, sempre, e pelos cuidados com o Pedro.

Agradeço aos meus pais, por todo o apoio.

Agradeço aos amigos vários, do Rio, São Paulo e da Bahia que de algum modo prestaram serviço ao que eu escrevia.

A Eliane, Vivian e Larissa: amores...

\section{E a muitas, muitas pessoas...}




\section{Resumo}

Machado, Leonardo Maia Bastos; Estrada, Paulo Cesar Duque. A formação do conceito de Imagem do pensamento na filosofia de Gilles Deleuze. Rio de Janeiro, 2009. 304 p. Tese de Doutorado - Departamento de Filosofia, Pontifícia Universidade Católica do Rio de Janeiro.

Neste trabalho, buscamos identificar a gênese do conceito de Imagem do pensamento em duas obras da primeira fase da filosofia deleuziana, Nietzsche e a filosofia e Proust e os signos. É nosso objetivo mostrar a importância central desse conceito para a elaboração do pensamento deleuziano e a evolução da filosofia de Deleuze verificada em torno desse tema. Assim, na primeira dessas duas obras, a imagem do pensamento liga-se à profunda renovação crítica da filosofia operada por Nietzsche e reivindicada também por Deleuze. Em Proust e os signos, verificamos um aprofundamento dessa concepção crítica, que agora, para além da filosofia, é operada a partir da não-filosofia, da literatura e, em particular, da obra proustiana. Trata-se, agora, de ligar a filosofia à não-filosofia, de criar uma interferência criativa entre esses dois planos, e de renovar nossa imagem do pensamento a partir dessa intercessão.

\section{Palavras-chave}

Imagem do pensamento; filosofia da diferença; filosofia transcendental; filosofia crítica 


\section{Abstract}

Machado, Leonardo Maia Bastos; Estrada, Paulo Cesar Duque (Advisor). The formation of image of thought's concept in Gilles Deleuze's philosophy. Rio de Janeiro, 2009. 304p. Doctoral thesis - Departamento de Filosofia, Pontifícia Universidade Católica do Rio de Janeiro.

The aim of this study is to identify the genesis of the concept of image of thought in two works belonging to Deleuze's first philosophical phase: Nietzsche and Philosophy and Proust and the Signs. In our reading of these works, we show the central importance of this concept for the elaboration of Deleuzian thought. We also confirm the importance of the concept in relation to the evolution of Deleuze's philosophy. In the first of these works, the image of thought is linked to the profound critical renewal of Nietzsche's philosophy as claimed by Deleuze. In Proust and the Signs, we observe a deepening of this critical conception which is operated from beyond philosophy, i.e. non-philosophy, literature and, in particular, the Proustian oeuvre. It is thus a matter here of linking philosophy to non-philosophy, creating a creative interference between these two planes, and renewing our image of thought from this intercession.

\section{Keywords}

Image of thought; philosophy of difference; transcendental philosophy; critical philosophy 


\section{Sumário}

1 Introdução

2 A imagem do pensamento em Nietzsche e a filosofia 20

2.1 Nota inicial 20

2.2 O filósofo sintomatologista: a ciência como sintoma e a 23 reprodução da metafísica

2.2.1 A crítica nietzschiana à natureza reativa da ciência moderna 23

2.2.2 A transformação da questão metafísica em Nietzsche 45

2.2.3 Pluralidade e perspectivismo: o funcionamento do método 54 nietzschiano

2.3 O Filósofo legislador: vontade, valor e criação de valores 67

2.3.1 Filosofia e vontade: o pensamento como um querer 67

2.3.2 A teoria da vontade de poder nietzschiana em relação à 69 dicotomia sujeito-objeto

2.3.3 Caráter afirmativo da vontade $\quad 77$

2.3.4 Vontade de poder e dialética 79

2.3.5 Caráter transcendental da vontade de poder 86

2.3.6 Uma nova axiologia: sentido e valor no pensamento 91 nietzschiano

2.3.7 Poder e vontade: a condição de sua ligação em Nietzsche 95

2.3.8 As más interpretações do poder na estrutura da vontade 97

2.3.9 A vontade em Schopenhauer 103

2.3.10 Filosofia da vontade e filosofia dos valores: Nietzsche contra 113 Kant

2.3.11 A filosofia como legislação: o filósofo legislador e a criação 118 de valores

2.4 O filósofo artista: vida e arte como culminação do projeto crítico 132 nietzschiano

2.4.1 "A existência tem um sentido?" 
2.4.2 A união entre pensamento e vida como tarefa do filósofo do 144 futuro

2.5 Por uma nova imagem do pensamento

3 A imagem do pensamento em Proust e os signos 163

3.1 Nota inicial

163

3.2 A interpretação deleuziana de Proust: sentido transcendental da 168 arte

3.2.1 Arte e crítica em Proust e os Signos

174

3.2.2 Filosofia e arte: o estatuto do pensamento em Proust e os 178 signos

3.2.3 Superioridade da literatura e da arte sobre a filosofia

181

3.3 Os signos

191

3.3.1 O problema dos signos

194

3.3.2 Signo e sentido

199

3.3.3 Presença e funcionamento dos signos na Recherche 201 proustiana

3.4 Os signos mundanos 205

3.5 Os signos do amor 213

3.5.1 Essência e interpretação dos signos do amor 218

3.6 Os signos sensíveis $\quad 228$

3.7 Da interpretação dos signos (seus problemas e insuficiências): 242 objetivismo, compensações subjetivas, a pesquisa das reminiscências

3.7.1 O problema das reminiscências 250

3.7.2 A memória involuntária 251

3.8 Os signos da arte - da superioridade da interpretação artística 257

3.8.1 Sentido dos signos artistas 271

3.9 O Aprendizado 272

3.10 Uma nova imagem do pensamento 285

4 Conclusão 296

5 Referências bibliográficas $\quad 298$ 